\title{
Dynamic Simulation of a Variable-Speed Ground-Coupled Liquid Desiccant Air-Conditioner for Use in Subtropical Regions
}

\author{
C. K. Lee and H. N. Lam
}

\begin{abstract}
The dynamic performance of a novel variable-speed ground-coupled liquid desiccant air-conditioner (VSGCLDAC) was analysed and compared with that of a conventional constant-speed ground-coupled heat pump (GCHP) in to the subtropical climate of Hong Kong. It was found that both the borehole length and the total energy consumption were reduced substantially. For the case of a multi-storey building, the VSGCLDAC could generally serve one more floor as compared to the GCHP system. Together with the enhancement of the indoor air quality, the VSGCLDAC was demonstrated to be a good choice for use in a low-rise building.
\end{abstract}

Index Terms-Borehole ground heat exchangers, ground-coupled heat pumps, liquid desiccant cycle, variable-speed control.

\section{INTRODUCTION}

Ground-coupled heat pump (GCHP) systems have gained wide acceptance in providing air-conditioning in Europe and USA [1] in which the applications in Europe are mainly heating-dominated. Recently, China has become one of the regions enjoying a rapid growth in the demand for such systems [2]. Usually, a vertical borehole ground heat exchanger borefield (GHE) is employed to exchange heat with the surrounding. With a more favourable temperature and thermal properties of the ground as compared to the ambient air, the energy efficiency of the GCHP systems is better than that of the corresponding air-cooled equipment. Fig. 1 shows the general arrangement of a vertical ground heat exchanger borefield. When GCHP systems are applied to a subtropical region like Hong Kong in which the annual air-conditioning load is cooling-dominated, excess heat is injected into the ground. This results in a gradual increase in the ground temperature which impairs the energy efficiency of the systems. To improve the situation, longer boreholes need to be installed. However, this will result in an increase in the initial cost and reduce the economic feasibility of the GCHP systems.

One way of solving the problem is to employ a hybrid design in which a partner system is used to share the condenser heat load with the GHE when the GCHP operates in the cooling-mode operation in summer. The cooling tower

Manuscript received December 31, 2012; revised February 12, 2012. This work was supported by the Research Grants Council of Hong Kong under the General Research Fund for Project Number 713710.

The authors are with the Department of Mechanical Engineering, University of Hong Kong, Hong Kong (e-mail: a8304506@graduate.hku.hk, hn.lam.hku@hku.hk). is commonly used as the partner system. A number of studies had been made in the design and analysis of this kind of hybrid system [3]-[7]. The main advantage of using cooling towers as the partner system is that they are cost effective. However, the use of fresh water cooling towers can increase the risk of Legionnaires' disease. Indeed, fresh water can be a scarce resource in some places. Sea water cooling towers are only applicable to the coastal regions. Consequently, other kinds of partner systems need to be explored. One alternative is to employ a cooling pond as the supplemental heat rejecter [8], [9]. Another way is to operate a GCHP system coupled with a liquid desiccant dehumidifier [10]. Lee and Lam [11] previously proposed a ground-coupled liquid desiccant air-conditioner (GCLDAC) in which a liquid desiccant cycle was integrated into a conventional GCHP so that part of the condenser heat could be used to regenerate the liquid desiccant.

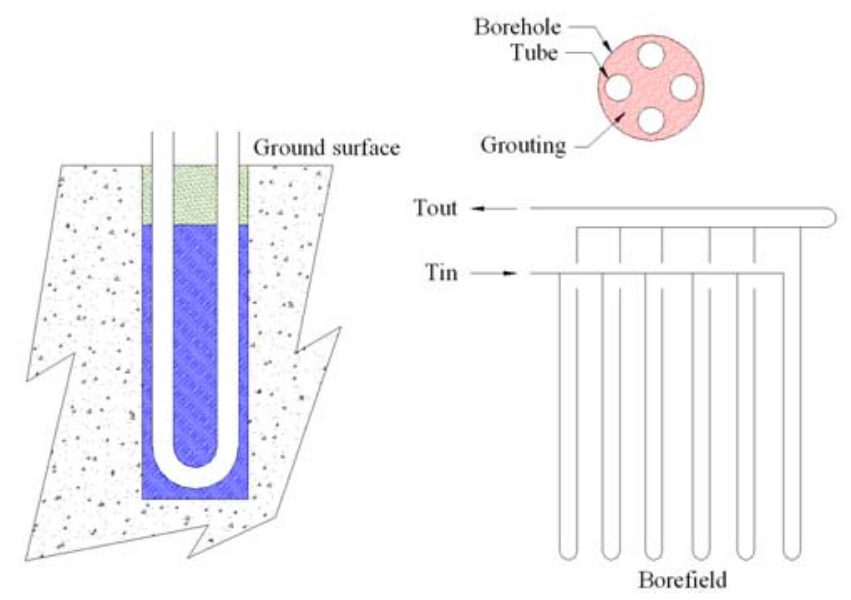

Fig. 1. General arrangement of a ground heat exchanger borefield

In order to reduce the borehole length, enhancement of the energy efficiency of the GCHP systems can be considered. One simple way is to control the compressor speed in order to modulate the capacity of the GCHP systems during the part-load operation. Various studies [12]-[16] had been made on the analysis of a variable-speed ground-coupled heat pump (VSGCHP) which helped indentify the range of operations in which energy-savings could be achieved. Meanwhile, Lee [17] investigated the dynamic performance of a VSGCHP system when applied to an office in three cities with different climates. It was concluded that both the energy consumption and the borehole length could be reduced which highlighted the benefit of using a VSGCHP system over the conventional GCHP system.

In Hong Kong, most of the buildings are multi-storey, and 
the available land area for installing the boreholes is usually limited to the building footprint. Hence, the reduction in the borehole lengths also implies that more floors can be served by the GCHP systems. This helps improve the operating range of the GCHP systems. To investigate ways to further reduce the borehole length, speed control is applied to a GCLDAC as used by Lee and Lam [11]. The dynamic performance of the new variable-speed ground-coupled liquid desiccant air-conditioner (VSGCLDAC) is analysed in this study on a multi-storey office building in Hong Kong. A comparison of the operating range is also made with that based on the conventional constant-speed GCHP system with various GHE configurations.

\section{MATHEMATICAL FORMULATIONS}

\section{A. Ground Heat Exchanger Borefield}

Fig. 2 shows the discretisation schemes adopted for the GHE as proposed by Lee and Lam [18]. A three-dimensional finite difference method was employed to calculate the ground temperature variation around the boreholes. The use of a rectangular coordinate system allows the entire GHE to be discretised in a single scheme so that the temperature variation in the entire GHE can be determined simultaneously. Each borehole is then represented by a square column with the square section circumscribed by the borehole radius. The fluid temperature variation inside each borehole is determined by dividing each borehole into various segments. An iterative approach is then used to calculate all the fluid temperatures and the borehole load profiles simultaneously based on the prescribed borehole temperatures. The borehole load profiles thus determined are used to compute the ground temperatures. The process is repeated until convergence is achieved.

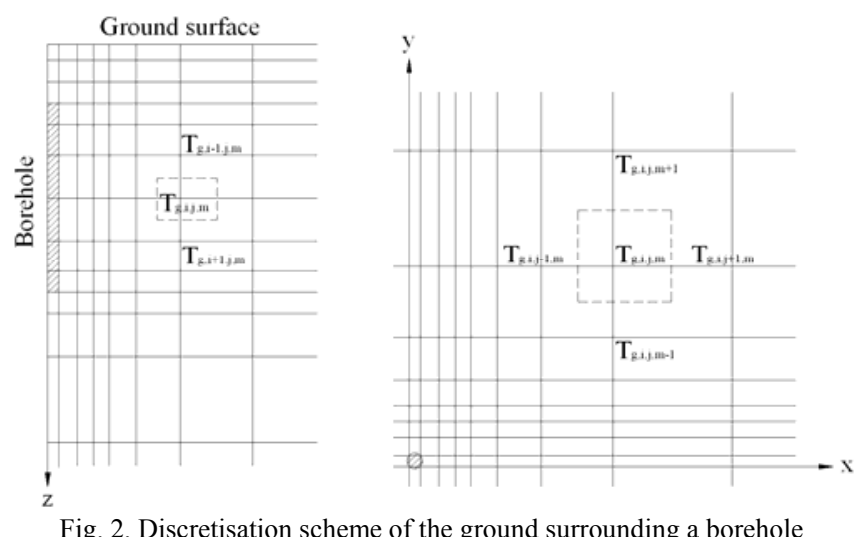

Fig. 2. Discretisation scheme of the ground surrounding a borehole

\section{B. Ground-Coupled Liquid Desiccant Air-Conditioner}

Fig. 3 shows the schematic diagram of a modified GCLADC under cooling-mode operation. Compared to the one adopted by Lee and Lam [11], two improvements have been made. The first is that the drier return air is employed in regenerating the liquid desiccant rather than the humid fresh air. The second is that all the hot refrigerant gas leaving the compressor passes the desiccant heater first before entering the ground-coupled coil. Meanwhile, all the cold saturated refrigerant mixture leaving the expansion valve goes into the supply air coil first before entering the desiccant cooler.
These design arrangements allow the temperature effect of the refrigerant to be fully optimised. The liquid desiccant cycle does not operate in the heating-mode operation. The modelling of the GCLDAC follows the one adopted by Lee and Lam [11] except for the refrigerant compressor on account of speed control considerations. Here, the parametric model detailed by Lee [17] for the compressor is used.

\section{Methodology of AnAlysis}

The same building zone of size $10 \mathrm{~m}$ (W) $\times 10 \mathrm{~m}$ (D) $\times 4 \mathrm{~m}$ (H) and design conditions as adopted by Lee [17] are employed in this study. The TRNSYS [19] simulation software is used to perform the year-round dynamic system simulations. In this study, new TRNSYS components are developed for the GHE and the VSGCLDAC. Both cooling and heating are provided by the VSGCLDAC. The weather data derived by Chan et al. [20] for Hong Kong is employed. To avoid the use of very deep boreholes, a $2 \times 2$ borefield is considered rather than a single borehole as adopted by Lee [17], but a double U-tube is still employed in this study. The required borehole lengths for a single floor based on both the VSGCLDAC and the constant-speed GCHP systems are compared under different values of the ground thermal conductivities when applied to a single floor. Finally, the operating ranges of both systems are analysed for application to a multi-storey building. Table I summarises the various parameter values used for the borehole. The undisturbed ground temperature is taken as $20^{\circ} \mathrm{C}$.

TABLE I: PARAMETER VALUES USED FOR THE BOREHOLE

\begin{tabular}{ll}
\hline \hline Parameter & Value \\
\hline Ground volumetric heat capacity $\left(\mathrm{kJ} / \mathrm{m}^{3} \mathrm{~K}\right)$ & 2160 \\
Borehole radius $(\mathrm{m})$ & 0.055 \\
Insulated length of borehole $(\mathrm{m})$ & 5 \\
U-tube outer radius $(\mathrm{m})$ & 0.016 \\
U-tube inner radius $(\mathrm{m})$ & 0.013 \\
Distance of tube centre from borehole centre $(\mathrm{m})$ & 0.03 \\
Fluid heat capacity $(\mathrm{kJ} / \mathrm{kg} \mathrm{K})$ & 4.19 \\
Fluid density $\left(\mathrm{kg} / \mathrm{m}^{3}\right)$ & 1000 \\
Fluid thermal conductivity $(\mathrm{W} / \mathrm{m} \mathrm{K})$ & 0.614 \\
Fluid dynamic viscosity $(\mathrm{kg} / \mathrm{m} \mathrm{s})$ & 0.00086 \\
Pipe thermal conductivity $(\mathrm{W} / \mathrm{m} \mathrm{K})$ & 0.4 \\
Grout thermal conductivity $(\mathrm{W} / \mathrm{m} \mathrm{K})$ & 1.3 \\
\hline \hline
\end{tabular}

\section{RESUlTS AND DisCUSSIONS}

\section{A. Fixing of Design Parameters for the VSGCLDAC}

To allow a fair comparison between the VSGCLDAC and the GCHP systems, the same compressor model, refrigerant mass, degree of superheat at compressor suction, supply air volume flow rate and borefield fluid mass flow rate were applied to both systems. The sum of the overall heat transfer value as well as the refrigerant volume of the desiccant cooler and the supply air coil were taken to be the same as those used for the evaporator of the GCHP. The same principle was applied to the desiccant heater and the ground-coupled coil. Table II summarised the parameter values used for the VSGCLDAC. 
TABLE II: PARAMETER VALUES USED FOR THE VSGCLDAC

\begin{tabular}{ll}
\hline \hline Parameter & Value \\
\hline Overall heat transfer value / refrigerant volume & \\
$\left(\mathrm{kW} / \mathrm{K} / \mathrm{m}^{3}\right)$ & $0.2 / 0.001$ \\
Desiccant cooler & $0.2 / 0.001$ \\
Desiccant heater & $1.3 / 0.0055$ \\
Supply air coil & $1.3 / 0.0055$ \\
Ground-coupled coil & 0.0003 \\
Volume of refrigerant in liquid line $\left(\mathrm{m}^{3}\right)$ & 1.5 \\
Refrigerant mass $(\mathrm{kg})$ & 0.621 \\
Swept volume of compressor $\left(\mathrm{m}^{3}\right)$ & 0.0149 \\
Volumetric coefficient of compressor & 1.126 \\
Polytropic coefficient of compression & 68.8 \\
Mechanical efficiency of compressor $(\%)$ & 5.56 \\
Degree of superheat at compressor suction $\left({ }^{\circ} \mathrm{C}\right)$ & 0.8 \\
Borefield fluid mass flow rate $(\mathrm{kg} / \mathrm{s})$ & 0.04 \\
Cross-sectional area of packed tower $\left(\mathrm{m}^{2}\right)$ & 0.3 \\
Height of packed tower $(\mathrm{m})$ & 0.01 \\
Equivalent diameter of packing (m) & 1.5 \\
Overall heat transfer value of desiccant heat exchanger & \\
(kW/K) & 0.05 \\
Desiccant solution volume flow rate at dehumidifier & \\
tower inlet (litre/s) & \\
\hline
\end{tabular}

The same design was applied to both the dehumidifier tower and the regenerator tower. The corresponding parameter values for the GCHP could be obtained by referring to Lee [17]. Based on the parameter values listed in Table II, the performance of the VSGCLDAC under design conditions and full compressor speed was given in Table III. It could be found that the borefield load in the cooling-mode operation was reduced by $17.77 \%$ when compared with a
GCHP of the same capacity and coefficient of performance $(C O P)$. This highlighted the benefit of the proposed system in relieving the annual borefield load unbalance. Indeed, this value was higher than those indicated in Lee and Lam [11] which was based on the previous design for the GCLDAC. This indicated that the modifications applied to the present design were effective.

\begin{tabular}{ll}
\multicolumn{2}{l}{ TABLE III: PERFORMANCE OF THE VSGCLDAC AT DESIGN CONDITIONS } \\
\hline \hline Parameter & Cooling / Heating \\
\hline Leaving fluid temperature $\left({ }^{\circ} \mathrm{C}\right)$ & $33.82 / 6.76$ \\
Unit capacity $(\mathrm{kW})$ & $13.37 / 12.68$ \\
Coefficient of performance & $4.57 / 4.51$ \\
Borefield load $(\mathrm{kW})$ & $12.65 / 10.77$ \\
\hline \hline
\end{tabular}

The design COP and capacity of the unit during the heating-mode operation was slightly lower than that in the cooling-mode operation. This was not surprising as only the supply air coil and the ground-coupled coil were used to provide heating. On the other hand, the desiccant cooler and heater were also employed to provide cooling. With smaller coil areas for heat transfer, the resulting COP and capacity in the heating-mode operation thus became lower. The overall effect on the year-round performance of the system depended on the run fraction of the unit in heating-mode operation. For an office building in a subtropical city like Hong Kong, this adverse effect could be expected to be small.

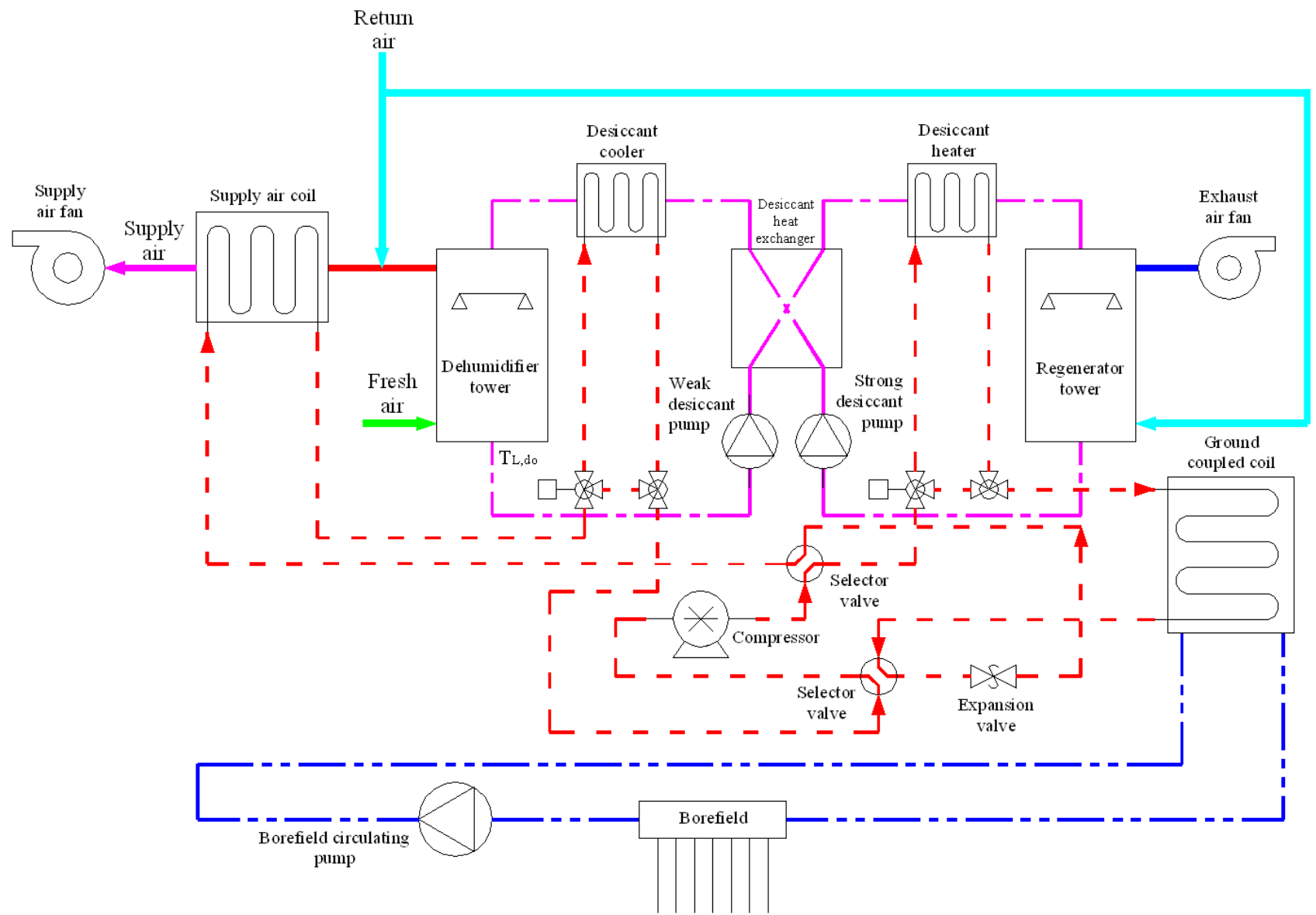

Fig. 3. Schematic diagram of the ground-coupled liquid desiccant air-conditioner in cooling-mode operation 


\section{B. Year-Round Performance of the VSGCLDAC System for a SINGLE-FLOOR Building Zone}

To perform the dynamic system simulation, the configuration of the GHE had to be specified. Based on the size of the building footprint, a borehole separation of $5 \mathrm{~m}$ was adopted for the $2 \times 2$ borefield. The remaining parameter to set was the length of each borehole. Here, the borehole length was selected based on a peak fluid leaving temperature of around $29^{\circ} \mathrm{C}$ after one year. Table IV compared the performances of the constant-speed GCHP and the VSGCLDAC systems with different values of the ground thermal conductivities for application to a single-floor building zone. The use of the VSGCLDAC resulted in a reduction in the borehole length which ranged from $24.7 \%$ to $25.6 \%$. The percentage saving was higher for a lower ground thermal conductivity. This amount was substantial which helped improve the operating range of the system for application to a multi-storey building.

TABLE IV: COMPARISION OF SYSTEM PERFORMANCES AT DIFFERENT GROUND THERMAL CONDUCTIVITIES

\begin{tabular}{lllll}
\hline \hline \multirow{2}{*}{ System } & $\begin{array}{l}\text { Ground } \\
\text { thermal } \\
\text { conductivity } \\
(\mathrm{W} / \mathrm{m} \mathrm{K})\end{array}$ & $\begin{array}{l}\text { Required } \\
\text { borehole } \\
\text { depth }(\mathrm{m})\end{array}$ & $\begin{array}{l}\text { Total } \\
\text { energy } \\
\text { demand } \\
(\mathrm{kWh})\end{array}$ & $\begin{array}{l}\text { Year-round } \\
\text { surplus heat to } \\
\text { the ground } \\
(\mathrm{kWh})\end{array}$ \\
\hline GCHP & 2.5 & 113 & 5796 & 30855 \\
& 3.0 & 102 & 5783 & 30858 \\
& 3.5 & 93 & 5784 & 30855 \\
VSGCLDAC & 2.5 & 84 & 4668 & 24215 \\
& 3.0 & 76 & 4563 & 24086 \\
& 3.5 & 70 & 4566 & 24085 \\
\hline \hline
\end{tabular}

The year-round system energy demand was reduced by around $20 \%$ with the use of the VSGCLDAC system. This showed that both initial and running cost could be reduced by employing of the proposed system. The year-round surplus heat injected to the ground dropped by around $22 \%$ which could help relieve the ground temperature buildup in the subsequent years of operation.

\section{Application of the VSGDLDAC System to a Multi-Storey Building}

When the VSGCLDAC system was applied to a multi-storey building, it was assumed that the activity and loading pattern in each floor were the same. Hence, only one zone model was needed to represent the dynamic response for each floor. With more floors to serve, the total GHE fluid mass flow rate and the borehole length would increase. In view of the specified internal diameter of the U-tubes, the maximum mass flow rate allowed for each borehole is roughly $0.8 \mathrm{~kg} / \mathrm{s}$. This meant that for a $2 \times 2$ borefield, only four floors at most could be served by the VSGCLDAC system. However, it was also limited by the maximum borehole length allowed. The determination of the maximum permissible depth for each borehole was generally an economic consideration which varied with the location of location. Indeed, the use of boreholes of up to $350 \mathrm{~m}$ had been reported [21]. In this study, a value of $200 \mathrm{~m}$ was selected.

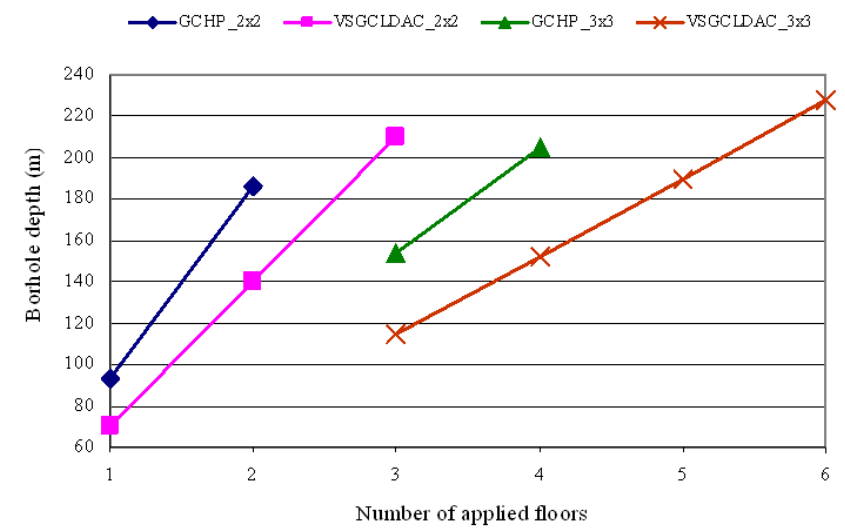

Fig. 4. Variation of the borehole depth with the number of applied floors for both systems

To further explore the capacity limit of the GHE, a $3 \times 3$ borefield with a borehole separation of $3.5 \mathrm{~m}$ was also considered. To avoid too low a fluid flow inside the U-tubes, the minimum number of applied floors was three for a $3 \times 3$ borefield. Fig. 4 depicted the variation of the borehole depth with the number of floors served for the two systems investigated. Here, the ground thermal conductivity was taken as $3.5 \mathrm{~W} / \mathrm{m} \mathrm{K}$. For the constant-speed GCHP system, a maximum of four floors could be served by using a $3 \times 3$ borefield. For the VSGCLDAC system, a maximum of five floors could be applied. The improvement in the operating range was not significant. The main reason was that the relief in the borefield load unbalance was not large enough even with the use of the VSGCLDAC system. The climatic condition was the major limitation. In the present analysis, the running time for heating accounted for less than $1 \%$ of the total operating hours of the system. It was therefore very difficult to shift the annual borefield load to a close-to-balance state. Nevertheless, it was still feasible to apply the VSGCLDAC system to premises with several storeys high like shopping malls and clinics. Indeed, the treating of the fresh air by the liquid desiccant enhanced the indoor air quality which could be an important consideration in specific applications.

\section{CONCLUSION}

In this study, a novel variable-speed ground-coupled liquid desiccant air-conditioner (VSGCLDAC) was proposed. The new system helped reduce the required borehole length by employing a desiccant cycle to share part of the condenser heat in summer. Moreover, the use of speed control to modulate the system capacity enhanced the energy efficiency of the system and decreased the loading to the ground heat exchanger borefield. The benefit of the new system over the conventional constant-speed ground-coupled heat pump (GCHP) system was assessed for application to the subtropical city of Hong Kong by performing year-round dynamic system simulations. Over a range of ground thermal conductivities considered, it was found that around $25 \%$ and $20 \%$ savings on the borehole length and the total energy consumption could be achieved for a single-floor building zone with the use of a $2 \times 2$ borefield respectively. The operating range improved mildly with the use of the new 
system when applied to a multi-storey office building. In general, one more floor could be served as compared to the cases when the conventional GCHP system was employed. Nevertheless, the proposed VSGCLDAC system was still a good choice for application to low-rise premises like shopping malls and clinics in the subtropical regions, particularly in view of the fact that the treating of the fresh air with the liquid desiccant could enhance the indoor air quality.

\section{REFERENCES}

[1] J. D. Spitler, "Ground-source heat pump system research-past, present and future," HVAC\&R Res., vol. 11, no. 2, pp. 165-167, 2005.

[2] Q. Gao, M. Li, M. Yu, J. D. Spitler, and Y. Y. Yan, "Review of development from GSHP to UTES in China and other countries," Renew. Sustain. Energy Rev., vol. 13, no. 6-7, pp. 1383-1394, 2009.

[3] S. P. Kavanaugh and K. Rafferty, Ground-Source Heat Pumps: Design of Geothermal Systems for Commercial and Institutional Buildings, Altanta: ASHRAE, 1997.

[4] S. P. Kavanaugh, "A design method for hybrid ground-source heat pumps," ASHRAE Trans., vol. 104, no. 2, pp. 691-698, 1998.

[5] C. Yavuzturk, "Modeling of vertical ground loop heat exchangers for ground source heat pump systems," Ph.D. thesis, Oklahoma State University, 1999

[6] Y. Man, H. Yang, and J. Wang, "Study of hybrid ground-coupled heat pump system for air-conditioning in hot-weather areas like Hong Kong,” Appl. Energy, vol. 87, no. 9, pp. 2826-2833, 2010.

[7] S. Hackel, G. Nellis, and S. Klein, "Optimization of cooling-dominated hybrid ground-coupled heat pump systems," ASHRAE Trans., vol. 115, no. 1, pp. 565-580, 2009.

[8] M. Ramamoorthy, H. Jin, A. D. Chiasson, and J. D. Spitler, "Optimal sizing of hybrid ground-source heat pump systems that use a cooling pond as a supplemental heat rejecter - A system simulation approach," ASHRAE Trans., vol. 107, no. 1, pp. 26-38, 2001.

[9] K. F. Lau and M. T. Suen, "Geothermal heat pump air-conditioning system for the Hong Kong International Wetland Park," in Proceedings of Shandong-Hong Kong Joint Symposium, 2003, pp. A1-A9.

[10] A. Gasparella, G. A. Longo, and R. Marra, "Combination of ground source heat pumps with chemical dehumidification of air," Appl. Therm. Eng., vol. 25, no. 2-3, pp. 295-308, 2005.

[11] C. K. Lee and H. N. Lam, "Computer simulation of ground-coupled liquid desiccant air conditioner for sub-tropical regions," Int. J. Therm. Sci., vol. 48, no. 12, pp. 2365-2374, 2009.

[12] S. P. Kavanaugh, R. S. Falls, and J. K. Parker, "A variable-speed ground-source heat pump," ASHRAE Trans., vol. 100, no. 1, pp. 1588-1596, 1994.
[13] L. Zhao, L. L. Zhao, Q. Zhang, and G. L. Ding, "Theoretical and basic experimental analysis on load adjustment of geothermal heat pump systems," Energy Convers. Manag, vol. 44, no. 1, pp. 1-9, 2003.

[14] H. Madani, J. Claesson, and P. Lundqvist, "Capacity control in ground source heat pump system part I: modeling and simulation," Int. J. Refrigeration, vol. 34, no. 6, pp. 1338-1347, 2011.

[15] H. Madani, J. Claesson, and P. Lundqvist, "Capacity control in ground source heat pump system part II: Comparative analysis between on/off controlled and variable capacity systems," Int. J. Refrigeration, vol. 34, no. 8, pp. 1934-1942, 2011.

[16] F. Karlsson and P. Fahlen, "Capacity-controlled ground source heat pumps in hydronic heating systems," Int. J. Refrigeration, vol. 30, no. 2, pp. 221-229, 2007.

[17] C. K. Lee, "Dynamic performance of ground-source heat pumps fitted with frequency inverters for part-load control," Appl. Energy, vol. 87, no. 11, pp. 3507-3513, 2010.

[18] C. K. Lee and H. N. Lam, "Computer simulation of borehole ground heat exchangers for geothermal heat pump systems," Renew. Energy, vol. 33, no. 6, pp. 1286-1296, 2008.

[19] TRNSYS, A Transient System Simulation Program, The Solar Energy laboratory, University of Wisconsin-Madison, 2006.

[20] A. L. S. Chan, T. T. Chow, S. K. F. Fong, and J. Z. Lin, "Generation of a typical meteorological year for Hong Kong," Energy Convers. Manag, vol. 47, no. 1, pp. 87-96, 2006.

[21] L. Rybach, M. Brunner, and H. Gorhan, "Swiss geothermal update 1995-2000," in Proceedings of World Geothermal Congress, Kyushu-Tohoku, 2000, pp. 413-426.

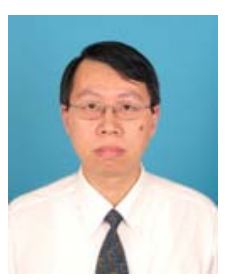

C. K. Lee is working as a senior research assistant at the Department of Mechanical Engineering, University of Hong Kong, Hong Kong (e-mail: a8304506@ graduate.hku.hk)

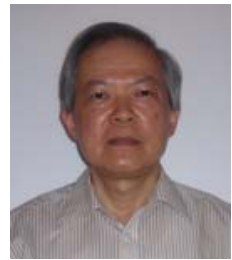

H. N. Lam is working as an associate professor at the Department of Mechanical Engineering, University of Hong Kong, Hong Kong (e-mail: hn.lam.hku@hku.hk). 